Article

\title{
Target Gutahuka: The UN's Strategic Information Intervention in the Democratic Republic of Congo
}

\author{
Jacob Udo-Udo Jacob \\ Communications and Multimedia Design, American University of Nigeria, PMB 2250, Yola, Adamawa State, Nigeria; \\ E-Mail: jacob.jacob@aun.edu.ng
}

Submitted: 2 February 2016 | Accepted: 7 April 2016 | Published: 4 May 2016

\begin{abstract}
This paper examines the nature and impacts of two information intervention radio programmes broadcast on Radio Okapi-the radio service of the UN Mission in the Democratic Republic of Congo. A matched randomization technique was used to assign Rwandan Hutus and Congolese autochthons in South Kivu to listen to either of the two programmes within their naturalistic contexts for 13 months. At the end of the treatment, participants' perceptions of barriers to peace; descriptive and prescriptive interventions; victimhood and villainity; opportunities for personal development and civic engagement; and knowledge of repatriation processes were assessed in 16 focus groups across four contexts. The study concludes that international media intervention programmes that provide robust information and a platform for objective analyses within a multiple narrative and participatory framework can enhance greater engagement with nascent democratic reforms, positive perception of long term opportunities for personal development and empathy with the ethnic Other.
\end{abstract}

\section{Keywords}

demobilisation; dialogue entre Congolais; disarmament; Gutahuka; repatriation

\section{Issue}

This article is part of the issue "International Broadcasting and Public Diplomacy in the 21st Century", edited by Gary D. Rawnsley (Aberystwyth University, UK).

(C) 2016 by the author; licensee Cogitatio (Lisbon, Portugal). This article is licensed under a Creative Commons Attribution 4.0 International License (CC BY).

\section{Introduction}

The war in the Democratic Republic of Congo (DRC) officially ended in 2002, but it has remained one of the world's worst humanitarian crises. 5.4 million people have died from war-related causes since 1998 (IRC, 2008), representing about $10 \%$ of the country's population, and two million people have been displaced (UNHCR, 2009). The involvement of combatants from neighbouring countries, particularly Rwanda makes the DRC conflict highly complex and intractable (Afoaku, 2002; Autesserre, 2006; Crises Group, 2009; Feeley \& Thomas-Jensen, 2008; Nest, Francois, \& Kisangani, 2006; Prunier, 2009; Swarbrick, 2004; Thakur, 2007; Turner, 2007).

Though the Rwandan conflict itself ended in 1994, it continued in the DRC when the Hutu genocidaires along with millions of Rwandan refugees crossed the border into the DRC. Despite the presence of some 20,000 UN peacekeepers, Rwandan Hutu militants continue to operate in the eastern region of the DRC principally under the banner of Forces Démocratiques pour la Libération du Rwanda or Democratic Forces for the Liberation of Rwanda (FDLR). There has also been the Rwandan Tutsi-led M23 armed group operating in North Kivu province. The UN Mission in the DRC (MONUC) ${ }^{1}$ is one of the world's largest UN Missions and the

\footnotetext{
${ }^{1}$ On May 282010 the UN Security Council adopted Resolution 1925 (2010) to extend the mandate of MONUC. Effective July 1 2010, Resolution 1925, renamed the Mission as the United Nations Stabilisation Mission in the Congo (MONUSCO). Still acting under Chapter VII of the UN Charter, MONUSCO places more emphasis on supporting and stabilising the DRC's military, law enforcement and justice institutions and consolidating the peace. Throughout this paper however, the old acronym MONUC is used to refer to the UN Mission in the DRC.
} 
most expensive. An essential element of MONUC's Public Information Operations (PIO) is Radio Okapi. Radio is easily accessible and is a very popular medium in the DRC. A rich oral tradition, low literacy rates, poor infrastructure (which limit the growth of other media such as television, newspapers and internet) are some of the factors that make radio the main communication medium in the DRC. These factors informed the focus of this research on the radio component of the UN Mission's PIO.

Moreover, the UN's Radio Okapi is unique in many ways. It is structurally and operationally different from previous UN Mission radio projects. Its operation is "outsourced" to a Swiss-based NGO-Hirondelle Foundation. While previous UN Mission radio stations were directly operated by the Mission's Public Information Department, Radio Okapi is operated by Hirondelle Foundation but under the authority of the Special Representative of the Secretary General and Head of MONUC. Interestingly, Radio Okapi sets its own news and information agenda.

Hirondelle Foundation has a policy of providing only objective and impartial information in crises areas. Contemporary understanding of the extent to which "objective information" can change prejudiced perceptions of the Other and violent behaviour is vague. Also limited is our understanding of what works in terms of the content of Information Intervention: the approach that provides objective information without any embellishments or the psyops approach broadly defined as planned operations to "convey selected information and indicators to foreign audiences to influence emotions, motives, objective reasoning" with the intention of inducing or reinforcing foreign attitudes and behaviour favourable to the originator's objectives (Joint Publications, 2010).

Within the UN itself there are contesting narratives and a seeming ambivalence over what approach works during peace support operations in crises states. JeanMarie Etter, Hirondelle Foundation's President, believes that "in the long run, in areas of violent conflict, an informative approach-which may have fewer results in the short term, but will be more solid and will build confidence in the long term-will eventually be preferred," (Domeniconi, 2004, p. 45). There has not been any empirical research on the ground to prove what approach works over time. Moreover, while there have been increasing interests on the role of the media in transforming conflicts in crises states, impacts of actual media intervention activities in ongoing conflicts have remained under-studied. The purpose of this study is to fill the gaps. It is a multi-method qualitative study-combining participatory, quasi-experimental and field based focus group methods. The study examines the nature and impacts of two intervention radio programmes broadcast on Radio Okapi. To build a clear picture of the ideological leanings of both organisa- tions, a series of interviews were conducted with leaders of Hirondelle Foundation and MONUC's Public Information Staff between November 2006 and March 2010. The interviews were unstructured. They were controlled dialogues between the author and the interviewees - in some cases face to face, in others by phone and in some other cases online using either Skype or email exchanges. Comments from the interviews and online exchanges provided a sound basis for defining and streamlining the core ideological debates of the study.

\section{The Significance of this Research}

This study is a reminder that radio as a communication medium is still a powerful tool of mass communication and indeed worthy of continued research. In an era where the Internet is the main buzz-word, researchers and research funders have been understandably more attracted to new media and Internet communications. With increasing interest and research funding going the way of online deliberation spaces, radio research is once again threatened with a return to the doghouse, to borrow Hilmes', (2002, p. 8) parody.

The study of radio has not been particularly attractive to $21^{\text {st }}$ century media scholars and indeed funders. The disinterest dates back a bit more. In the past four decades, the study of popular culture has bloomed. But this bloom has unfortunately excluded Radio. Michele Hilmes attributes what she calls the negative "academic legitimation" of radio since the 1960s to the medium's "cultural marginality" and "low brow roots" (2002, p. 6). Indeed, since the late 1960 s Radio has increasingly been considered as low profile and inferior to other more technologically enhanced media such as Television. By the 1970s, as Hilmes has noted, industrially, culturally, historiographically, and theoretically, Radio had been rendered invisible by the temper of the times. But Radio's ostensible degeneration into a "vast cultural wasteland" (Squier, 2003, p. 1), did not apparently affect international radio because it actually bloomed during the cold war as a tool for propaganda and public diplomacy. During the cold war, Radio Free Europe, the VOA, the BBC and other International broadcasters expanded and took on more strategic importance in the international affairs departments of sponsor nations. Rawnsley has substantially filled the gaps on the use of radio as a propaganda tool during the cold war $(1999,1996)$.

As a tool for psyops, public and cultural diplomacy, "surrogate radio" continues to occupy the attention of key Western Governments and their intelligence agencies in borderlands including Afghanistan, Iraq, Iran, etc. This work calls to mind that in Africa, beyond the realms of Western Governments' use of radio for strategic purposes, radio remains the most popular medium of communication-used frequently by the UN, 
NGOs and Governments to reach citizens. Its misuse during the Rwandan genocide demonstrates its potentials. A strong oral tradition, a social and cultural fondness for storytelling, and devotion to radio borne out of absence of other means of mass communication, makes radio a potentially powerful tool for transforming conflicts not only in sub-Saharan Africa but also in North Africa and the Middle East.

Moreover, radio impels the Pan-African philosophy of Ubuntu-inspiring sharing, commonality and communitarianism. Group listenerships to radio in rural areas provide a meeting point for exchange of stories and affinity, but more importantly a key anchor-point for sharing-sharing not only the radio receiver and the listening processes, but also meaning. This study draws attention to this reality about Africa and harps on the imperatives of designing Information Intervention approaches that leverage on these elements. The work argues that the approach in Africa has to depart from the Western perception of an individualised radio audience or "listener". Ethnographic observation of radio listeners in Uvira in South Kivu province of eastern DRC showed that radio audiences are not aggregates of individuals but are social entities bound together by shared histories, cultural ties and local epistemes. Media messages are consumed not individually, but collectively. Meaning is collectively negotiated and shared among culturally inter-dependent beings. This has farreaching implications on the design and implementation of information contents for audiences in rural Africa. Current Western libertarian approach of seeking to achieve psychological impacts on "individuals" will have to give way to a more interactive approach aimed at achieving social impacts.

\section{Background to the UN's Information Intervention in the DRC}

It is necessary to emphasise the importance of the Disarmament, Demobilisation, Repatriation, Rehabilitation and Reintegration (DDRRR) programme to the transformation of the DRC conflict. It is critical to our understanding of conflict transformation processes in the DRC because the presence of thousands of armed militia from neighbouring Rwanda has been the main reason for the endurance of the DRC conflict. Indeed, the presence of foreign armed groups is damaging to internal security in the DRC. It also represents a standing obstacle to the improvement and normalisation of relations between the DRC and its neighbours. (Swarbrick, 2004). The objective of the DDRRR programme is to solve this problem. The central purpose of MONUC's Mission after the successful conduct of general elections in 2006 was how to control the situation in the eastern DRC where most of the Rwandan Hutu FDLR elements are based. Moreover, other militant groups refused to disarm while the FDLR exists.
After the Lusaka ceasefire agreement was signed with belligerent forces in the DRC in 1999, MONUC was mandated by the Security Council under Chapter VII of the UN Charter to enforce the agreement. Paragraph 8.2.2 of the Lusaka Agreement had envisaged that the UN Mission would be involved in "tracking down and disarming armed groups...working out such measures, persuasive or coercive, as are appropriate for the attainment of the objectives of disarming, assembling, repatriation and re-integration into society of members of the armed groups" (1999, para. 8.2.2e). MONUC however chose to principally pursue the "persuasive" rather than the "coercive" element of the agreement particularly regarding the disarmament and repatriation of FDLR elements in eastern DRC. According to Swarbrick (2004) this was the point where MONUC differed significantly in its approach to DDRRR from what was envisaged by the Lusaka agreement.

A hint to the UN's DDRRR approach was given in the July 151999 Report of the Secretary General on the UN Preliminary Deployment in the DRC. The report noted that "a purely military solution appears to be impossible, if only because the forces most able and willing to impose a military solution have clearly failed to do so" (para. 22). Instead of military engagement, the Secretary General noted the need for the establishment of a well-funded, well planned and long term programme of disarmament and demobilisation, but emphasised the need for a robust public information component- "the benefits of such a programme will need to be widely publicised in order to attract the fighters now under arms" (para. 24). This has underlined the UN's strategic communications approach to DDRRR in the DRC.

The radio magazine programme, Gutahuka ("go back home" in Kinyarwanda) was created specifically for the purpose of persuading ethnic Hutu combatants to voluntarily surrender and join the DDRRR process. MONUC's Spokesman, Madnodje Mounoubai said the founding purpose of Gutahuka was to speak to "individual combatants" of the FDLR in particular and Rwandan Hutus in the DRC in general to lay down their arms and return home. According to him, Gutahuka is an "alternative to military pressure" and was designed to fulfil the DDRRR mandate of the mission. He said Gutahuka is "a response to the difficulties to reach the FDLR combatants and an attempt to get information to non-combatants...to provide them with information on how they can go back to their country on a voluntary basis" (M. Mounoubai, personal communication, March 9, 2010).

It is important to point out that whereas other programmes on Radio Okapi are produced by Hirondelle Foundation staff, Gutahuka on the other hand is produced directly by MONUC. It is broadcast once a day in the early hours, Monday to Saturday. Gutahuka specifically targets Rwandan Hutus in Eastern DRC and seeks to convince them, particularly FDLR combatants, to re- 
turn to Rwanda. The programme can be roughly grouped into three segments. The first explains the DDRRR process and the second segment features "true stories" of ex-combatants who have returned to Rwanda. Families of ex-combatants as well as former FDLR Commanders that have returned are also interviewed in the second segment. Usually they talk of conditions in the Rwandan homeland and urge fighters to set aside their fear and return. The third segment is the call by the narrator on combatants to take up MONUC's offer of repatriation while it is still possible. Gutahuka conveys three levels of normative appeals: Descriptive Norms, Injunctive Norms ${ }^{2}$ and Subjective Norms. As shown in Figure 2, the programme also explains the DDRRR processes and the financial benefits involved for returnees depending on their status.

By interviewing ex-combatants and their extended family members, perceived norms are tied to the group identity of not only the FDLR network but also the Hutu ethnic group, to appeal as it were, to their sense of oneness, not only as a rebel network but also as a family. In every edition of Gutahuka, MONUC fulfils Rimal and Real's definition of descriptive norms in seeking to influence perception about "individuals' beliefs about how widespread a particular behaviour is among their referent others" (2003, p. 185). On the other hand, Hirondelle Foundation, as earlier pointed out, prefers an approach that provides objective information and rigorous debates among contending factions, so that audiences can make their own decisions (Jacob, 2010, 2015).

This study maps the discourses and impacts of the contending ideologies through the prism of two radio programmes that represent the two ideological leanings. The two intervention radio programmes studied in this research are: Dialogue entre Congolais (Dialogue between Congolese) and Gutahuka. Dialogue entre Congolais (Dialogue hereafter) is a political newsmagazine programme broadcast twice daily, Monday to Friday, on Radio Okapi. It explains the peace process and gives opportunities to belligerents to discuss their grievances openly. It is produced by Hirondelle Foundation's Radio Okapi staff. It can be argued that the communication philosophies or ideologies of MONUC and Hirondelle Foundation are represented and reproduced in Gutahuka and Dialogue respectively.

\section{Methodology}

In assessing the nature of impacts of the two programmes, "influentials" among Congolese autochthons and Rwandan Hutus across four towns in South Kivu, eastern DRC (Fizi, Mwenga, Uvira and Walungu) were selected using a refinement of Eric Nisbet's (2006) engagement model of opinion leadership. From the influ-

\footnotetext{
2 Injunctive norms describe consequences for non-compliance with a prescribed form of behaviour.
}

entials' pool, a matched randomization technique was used to assign Hutus and autochthons in South Kivu to listen to either one of the two radio programmes within their naturalistic contexts for a period of 13 months. Autochthon control groups listened to Gutahuka while Hutu control groups listened to Dialogue. Peer researchers, selected from the participants were trained to monitor listenership for the entire period. At the end of the treatment, outcomes of perceptions of barriers to peace; perceptions of descriptive and prescriptive interventions; perceptions of victimhood and villainity; perceptions of opportunities for personal development and civic engagement; attitudes toward members of other ethnic groups as well as knowledge of MONUC's DDRRR processes were assessed in a total of 16 focus groups moderated and recorded by the peer researchers. The peer researchers were fully trained for their responsibilities.

Focus group membership was restricted to a maximum of 10 participants to avoid overcrowding. A matched randomization technique was used to assign participants to focus groups based on sex, age, combat status and civic status. This technique helped to reduce inter-group heterogeneity. Tables 1 and 2 show the demographic characteristics of participants at the focus groups in the two networks.

Focus group comments (which were recorded verbatim) were analysed and integrated to show patterns and inter-relationships across contexts and networks and subsequently interpreted within the larger structure of the research enquiry.

This methodological approach was chosen because of lessons learned from the limitations of most media influence studies very aptly outlined by McGuire (1986) to include no clear measurement of exposure to the media programme and poor or no clear measurement of a causal relationship between the programme and the outcome. To transcend these limitations, a laboratory-based approach seems ideal. However, while laboratory-based experiments with their implicit controls and artificiality can precisely map causal impacts, they lack the ability to compensate for the psychodynamic variables that underlie the actions of combatants and the interactions between militants and/or villains and victims in a conflict situation. Moreover, variables of the "real world situation" such as the social semiotics of the conflict itself, including media reports and the knowledge thereof; rumours and other socially transmitted information; emotions of fear, guilt, anger, trauma and sadness due to personal loss or even rape are ignored in laboratory studies. Paluck (2007) who has used a similar approach combining field observational and experimental methods writes that "artificiality is particularly damaging in media impact because media consumption is truly the sum of all its social and phenomenological parts" (p. 24). On the other hand, while field-based studies using observational, focus group or 
Table 1. Demography of Hutu ethnic network Focus Group discussants.

\begin{tabular}{lllllllll}
\hline Contexts & Uvira & \multicolumn{3}{c}{ Walungu } & \multicolumn{2}{c}{ Fizi } & \multicolumn{3}{c}{ Mwenga } \\
\hline Programme & $\mathrm{G}$ & $\mathrm{D}$ & $\mathrm{G}$ & $\mathrm{D}$ & $\mathrm{G}$ & $\mathrm{D}$ & $\mathrm{G}$ & $\mathrm{D}$ \\
Mean Age & 32 & 33 & 38 & 36 & 32 & 31 & 32 & 33 \\
Sex (\% women) & 30 & 30 & 30 & 30 & 30 & 30 & 40 & 30 \\
$\begin{array}{l}\text { Combat Status (\% ex- } \\
\text { combatants) }\end{array}$ & 40 & 40 & 20 & 20 & 50 & 50 & 30 & 30 \\
$\begin{array}{l}\text { Civic Status (\% Mar- } \\
\text { ried/Co-habiting }\end{array}$ & 30 & 30 & 20 & 20 & 20 & 20 & 30 & 30 \\
$\begin{array}{l}\text { Cellule Listenership } \\
\text { Compliance (\%)* }\end{array}$ & 100 & 98 & 98 & 97 & 98 & 96 & 95 & 94 \\
$\mathrm{~N}$ & 10 & 10 & 10 & 10 & 10 & 10 & 10 & 10
\end{tabular}

Notes: Sample demonstrating balance between listening groups in Hutu Groups. G = Gutahuka listening cellule; $\mathrm{D}=$ Dialogue listening cellule. *Cellule Listenership Compliance (CLC) percentages were derived from participants' recordings of listenership in their monthly log-book returns in each cellule.

Table 2. Demography of autochthon network Focus Group discussants.

\begin{tabular}{lllllllll}
\hline Contexts & Uvira & \multicolumn{3}{c}{ Walungu } & \multicolumn{2}{c}{ Fizi } & \multicolumn{3}{c}{ Mwenga } \\
\hline Programme & G & D & G & D & G & D & G & D \\
Mean Age & 43 & 42 & 33 & 33 & 33 & 34 & 32 & 31 \\
Sex (\% women) & 30 & 30 & 30 & 40 & 30 & 40 & 40 & 40 \\
$\begin{array}{l}\text { Combat Status (\% ex- } \\
\text { combatants) }\end{array}$ & 0 & 0 & 30 & 30 & 20 & 20 & 10 & 10 \\
$\begin{array}{l}\text { Civic Status (\% } \\
\text { Married/co-habiting) }\end{array}$ & 80 & 80 & 50 & 50 & 60 & 60 & 70 & 70 \\
$\begin{array}{l}\text { Cellule Listenership } \\
\text { Compliance (\%)* }\end{array}$ & 91 & 97 & 80 & 87 & 86 & 90 & 76 & 78 \\
N & 10 & 10 & 10 & 10 & 10 & 10 & 10 & 10
\end{tabular}

Notes: Sample demonstrating balance between listening groups in Autochthon Groups. G = Gutahuka listening cellule; $\mathrm{D}=$ Dialogue listening cellule. *Cellule Listenership Compliance (CLC) percentages were derived from participants' recordings of listenership in their monthly log-book returns in each cellule.

interview techniques parade the real world situation, they are restricted in terms of their competence in mapping out clear causal pathways that link exposure with response. Also, it is usually based on self-reported exposure which may not be accurate. Moreover, one of the setbacks with most media impact researches, despite whatever technique used, is the tenure of exposure. Such studies are usually too brief to capture the entire process of exposure. The duration and/or repetition of the media programme are rarely captured whereas most media intervention programmes run over a long period of time. Gutahuka and Dialogue for instance have been broadcasting for over seven years. This length of time as Paluck $(2007,2009)$ has suggest- ed can introduce reinforcements and familiarity effects on the relationship between presenter and listener thus engendering feelings of loyalty and emotional attachment to the programme. It can also create apathy or even resentment.

Furthermore, because of the conflict situation in the DRC (involving clandestine and guerrilla armed groups) and the peculiar foreigner/indigene crises in South Kivu, a research methodology that draws maximally on ethnic membership is imperative. A participatory approach involving the communities researched offered a unique opportunity for monitoring listenership in the first instance; for frankness and reflexive engagement with questions during focus group discus- 
sions within a setting that is inartificial and uninterrupted by "outsiders". Moreover, focus group moderation by trained peer researchers recreated contextually organic social conversations which were critical to the research.

\section{Findings and Discussion}

\subsection{Perception of Prescriptive Transformations in Dialogue Listening Groups}

When asked about their beliefs concerning what needed to be done to achieve peace and development in their communities in particular and the country in general, an interesting pattern emerged in Dialogue groups' comments across the two ethnic networks. The comments reflected the salient themes in the programme Dialogue. Participants did not express specific ways and means through which sustainable conflict transformation (or peace and development) can be achieved in their communities or in the region but in all contexts they talked about structural elements which they linked to poor leadership both at regional and national levels. In two of the contexts, (Uvira and Mwenga) corruption was specifically mentioned as one of the main impediments to conflict transformation-a salient topic on Dialogue. This pattern significantly departs from the control group where participants across contexts mostly talked about relational issues of autochthony and allochthony (foreigner). Basically, autochthon Gutahuka listeners reasoned that if foreigners (primarily Rwandan Hutus) left the country, there would be peace-reflecting the underlying meaning of Gutahuka's "go back home" message.

The emerging implication here is that Dialogue participants perceived prescriptive transformations along the trajectory of structural interventions not necessarily within the rubric of immediate issue or relational concerns such as presence of foreigners, but on the imperatives of credible political leadership. While immediate issue concerns are by no means less important or less urgent, an understanding of the imperatives of credible leadership in transforming the problems of the DRC suggests a collective consciousness of the role of a legitimate or democratically elected government in transforming deep-seated socio-political issues. This is important in a country that has seen over 40 years of corrupt authoritarian government out of some 55 years of independence. It suggests a new appreciation of values of good governance and accountability. The sharp contrasts between their beliefs and those of their contemporaries and in some cases neighbours and close Others that listened to Gutahuka during the period validates the influence of the programmes on participants' opinions regarding issues that concerned them and their normative beliefs about transformation.

\subsection{Engagement with New Democratic Values and Reforms in Dialogue Groups}

In addition to patterns of more factual, logical and objective expressions of perceptions of barriers to peace and a deeper understanding of structural conflict transformation factors, perception of civic engagement was investigated in relation to Gutahuka control groups. Across the two ethnic networks, Dialogue participants' comments showed a greater sense of responsibility and ownership of democratic reforms. When commenting on their engagement with community selfhelp projects and new democratic processes they used words such as "my responsibility" (Walungu Group), "an obligation" (Fizi Group), "our community" (Mwenga). There was also evidence of participants' involvement in civic duties and other active expressions of civic engagement during the course of the programme. For example in Walungu, an autochthon participant said he has started calling-in during phone-in programmes on the local radio although he said it was expensive to make the phone calls, but added "If I don't do it who would? We can't leave it and hope that somehow those up there would know what we think" (Walungu Group). In Uvira another autochthon Dialogue participant said he has recently (during the course of the listenership) taken part in a conflict resolution meeting organised by MONUC's Joint Protection Teams (JPTs) in Uvira where he had opportunity to talk about communal issues of interest and wished there were more of such opportunities. Also, a Dialogue participant in Fizi said his church is involved in supporting de-mining activities, but although he is not directly involved since it is not in his hometown, he believed it was an obligation to take part in community efforts such as building schools, maternal care and birth centres among others. Across all contexts and networks, Dialogue participants perceived themselves as stakeholders in their society's wellbeing. Another interesting pattern is that participants in Dialogue groups all linked opportunities for personal development to stability, peace and development in their region. Expressions used included: "if there are roads and security..." (Uvira group); "if things are stable..." (Fizi group); "security on the roads..." (Walungu group) and "there has to be peace first" (Mwenga group).

Another pattern noticed across contexts among the Dialogue participants was the perception of civic engagement as needful. They also had a positive perception of opportunities for their personal development in the DRC as well as a sense of optimism or hope for a better future for their communities. This cannot be said to be the case with Gutahuka listeners who in most contexts were more inclined towards short-term needs such as "food in the stomach" (Walungu group), "worried about my own stomach" (Fizi group) etc. The implication is that Dialogue listeners linked attainment 
of their personal development goals with a stable society in the DRC. Stability is constructed within frames of not only absence of war, but also infrastructural development-roads, bridges as well as general security. This explains their perception of themselves as stakeholders in their community's wellbeing. Patterns in beliefs expressed in Gutahuka groups in both networks were fundamentally different. Participants did not talk about any civic engagement activity there were involved in. Their comments suggested that they perceived politicians as being responsible for the wellbeing of their community and that the political system offered no opportunities for civic engagement.

Expressions of normative beliefs about new democratic values and descriptive interventions by Hutu Dialogue listeners show a pattern that matches those of autochthon listeners. In their discussion of descriptive interventions, Hutu Dialogue listeners firstly, displayed very good knowledge of ongoing intervention efforts of the DRC government (although they believed the interventions were weak and half-hearted); secondly there was a pattern of Hutu Dialogue listeners claiming a stake or ownership of transformation processes. Although they all acknowledged that political participation for them is limited by their identity and restricted citizenship, they were as optimistic as the autochthon Dialogue groups of the DRC government's ability to fix the issues if things were done right. Unlike Gutahuka listeners across both networks, Hutu Dialogue listeners across contexts saw intervention activities as being within the trajectory of the DRC's elected government. This supports patterns observed among Autochthon listeners who saw credible political leadership as an essential element in conflict transformation processes. Among both autochthon and Hutu Dialogue listeners there is a strong pattern of engagement, a sense of ownership and relatively greater factual, logical and objective expression of issues.

Moreover, autochthon Dialogue listeners expressed a more favourable attitude toward Rwandan Hutus than did autochthon Gutahuka listeners. When asked about what they imagined their relationship with the ethnic Other would be in the future, Dialogue participants talked mostly about the impediment of Citizenship. Participants said there was no systematic framework and transparency of regulations for attaining citizenship which has been used as a political tool by successive governments in the DRC. There was the underlying reasoning among Dialogue participants across contexts that when crises of citizenship are resolved, communities could then decide to forge ahead together as a people.

The most revealing expressions of autochthon Dialogue participants' attitude toward Hutus was in their comments about who they felt were the worst victims of the conflicts. There was an interesting pattern across all contexts of autochthon Dialogue listenership groups. All groups talked about Hutu refugees as being among the worst victims of the conflict. The empathy with Hutus was strong among participants and evident in their tone. For example in Fizi, a participant said "It is hard not to feel for them (Hutus)...haunted and hated by everyone". In Uvira, a participant expressed a view that is very rarely expressed among non-Hutus: "genocide has been committed against them (Hutus) but everyone is talking about Tutsi genocide". In Walungu, participants said no one can ever tell what Hutus have gone through since they fled Rwanda in 1994. These sentiments were in contrast with those expressed by the control Gutahuka listening groups. In the autochthon Gutahuka groups, there was no mention of Hutus as victims of the conflict at all. But women (mainly pregnant women) were identified as the worst victims. Also, with exceptions in Fizi, autochthon Gutahuka listeners across all contexts wanted all Rwandans-both Hutus and Tutsis to leave. When asked to talk about their imagination of future relationships with other ethnic groups, again except in Fizi, Gutuhuka listeners said they did not think it would ever be possible for all ethnic groups to integrate and live together peacefully as a community. They also said it would not be possible to have a unified army involving all the ethnic groups because they thought it would be difficult to get all the groups to transcend their personal interests and that of their ethnic groups to work together within a unified Congolese security force. Again there was an exception in Fizi on this. Overall, participants across listening groups in Fizi felt far more comfortable with the ethnic Other than participants in the other contexts. This is possibly because in Fizi, there has been a long history of mutually beneficial relationships between Hutus and autochthons not only in inter-marriage but also in trade. For years, both groups have lived side by side with each other and conflicts have been very minimal between them. Indeed, in Fizi, MONUC does not even have the kind of robust presence such as Joint Protection Teams and Company Operational Bases (COBs) deployment like they do in the other towns. This illustrates the relative calm in the territory when compared with the other towns.

Among Congolese autochthons there is a strongly noticeable pattern of contrasts between both listening groups' perceptions of Hutus. There is a pattern of empathy and constructive engagement evident in Dialogue listeners' attitude towards not only Hutus but also the ethnic Other in general, but most noticeably among the Hutus. Perceptions of Hutus as victims of the conflict reflect a sense of empathy with the Hutu refugees in their communities. Granted, expressions of sympathy may not necessarily reflect actual sympathetic attitude of listeners toward Hutus, but they are suggestive of what they think about the Hutus which in turn inform attitude. Furthermore, the discussion approach used in the focus groups was designed to assess attitudes through cognitive processes and not direct 
questioning. So participants did not (in this case) have to answer direct attitude measurement questions such as "what do you think of the Hutu?" But they had the latitude to talk about whoever they felt were affected or afflicted most by the DRC war. A pattern in answers across contexts suggest a linkage between the programme listened to and perceptions of victimhood in general and victims of the conflict in particular. Dialogue participants expressed the need for a process where Hutus can access Congolese citizenship. Citizenship in the $\mathrm{DRC}$ is a highly politically contested issue. This is because it confers various rights, benefits and entitlements including land ownership. So this further shows that they have a positive attitude toward Hutus in contrast to Gutahuka listeners who believed integration both at the community level and within the army was impossible.

Arguably, Dialogue can positively influence regular autochthon listeners' attitude toward Rwandan Hutus. This is attributable to the transactional nature of the programme. The programme is based on a model that illustrates mass communication as a horizontal or transactional process. By creating a platform for rigorous debates of key issues that confront the community as a whole, the programme encourages audiences to participate in evaluating the current situation, to perceive the current situation based on the different positions debated and to interpret the debates in a way that fits their own peculiar episteme. This interpretation can either lead to convergence or divergence within the communication network (please see Kincaid 1993; Rogers, 1995; Rogers \& Kincaid, 1981).

Indeed, Dialogue represents a transactional media regime that draws on communitarian media values. It seeks to collectively negotiate social construction of the common good and engages Radio Okapi as a member of the community-constantly debating and exploring the common good. Regular exposure of community members to Dialogue created a new reality or new sets of mediated norms among listeners, built not necessarily on the historically dysfunctional patterns of social relations or solely on the subjective norms of political elites or guerrilla entrepreneurs, but on a reconditioning of objective and subjective norms using the tools of credible and interactive media. Objective norms are ongoing events that constitute the bases or backdrop for discussions in Dialogue. Subjective norms purveyed by elites are refined into a more transactional mode-involving debates on the issues rather than the top-down peddling of subjective norms in Gutahuka. These have implications on contemporary debates on the normative role of the media particularly in crises societies, and its influence on beliefs and attitudes toward the Other.

\subsection{Process of Perception Change in Dialogue Groups}

It is very important to explore in greater detail how Dialogue influenced perceptions and attitudes of listeners so significantly. The paper will argue that this was achieved through a transactional process of exposure to information about the current situation, ideation, interpretation and (re) evaluation of ongoing events or current situation-to achieve changes in personal perceptions.

\subsubsection{Exposure to Current Situation}

By first talking about the event to create a background to the debates, Dialogue exposed listeners to the $o b$ jective reality of ongoing events at local, national and regional levels (or current situation) with its implicit inter-relationships. Participants were also directly exposed to some of the events through either the media or during their daily lives.

\subsubsection{Ideation}

Ideation involves evolution of knowledge of the issues in contention as selected, clarified and discussed in Dialogue. It connotes a knowledge process that evolves along with exposure to ongoing events, clarification, discussion and personal evaluation of the issues debated on Dialogue. Ideation was achieved at three transactional levels-first direct exposure to ongoing events or objective reality; secondly, exposure to clarifications and discussions in Dialogue; and thirdly, through a process of personal evaluation and re-evaluation conditioned by personal interpretation, clarifications, discussants' perspectives and proposals on Dialogue (please see Figure 1). Ideation was not constant but dynamic-constantly changing along with a constantly changing objective reality and the (re)evaluation thereof. Constantly evolving events, debates arguing for different sides of the issues not only enhanced ideation but also led to series of evaluations and re-evaluations both at personal and group levels. In the perception process, ideation was constantly refined by exposure to real world events (and the variables that underlie them), as well as exposure to reconstructed versions or debates of some of those events on Dialogue. Exposure to reconstructed realities in turn conditioned participants' interpretation of objective realities. There were indeed cases where participants used the same arguments, logic and phrases used by their preferred Dialogue discussants to buttress their points during focus group discussions. The process of ideation also underlined participants' understanding and interpretation of the issues which led to either their disbelief or affirmation of previous beliefs or even adoption of a whole new set of beliefs. Importantly, knowledge derived from clarified discussions of issues on Dialogue enhanced an understanding of the Other's issues hence potentially achieving mutual understanding and agreement. 


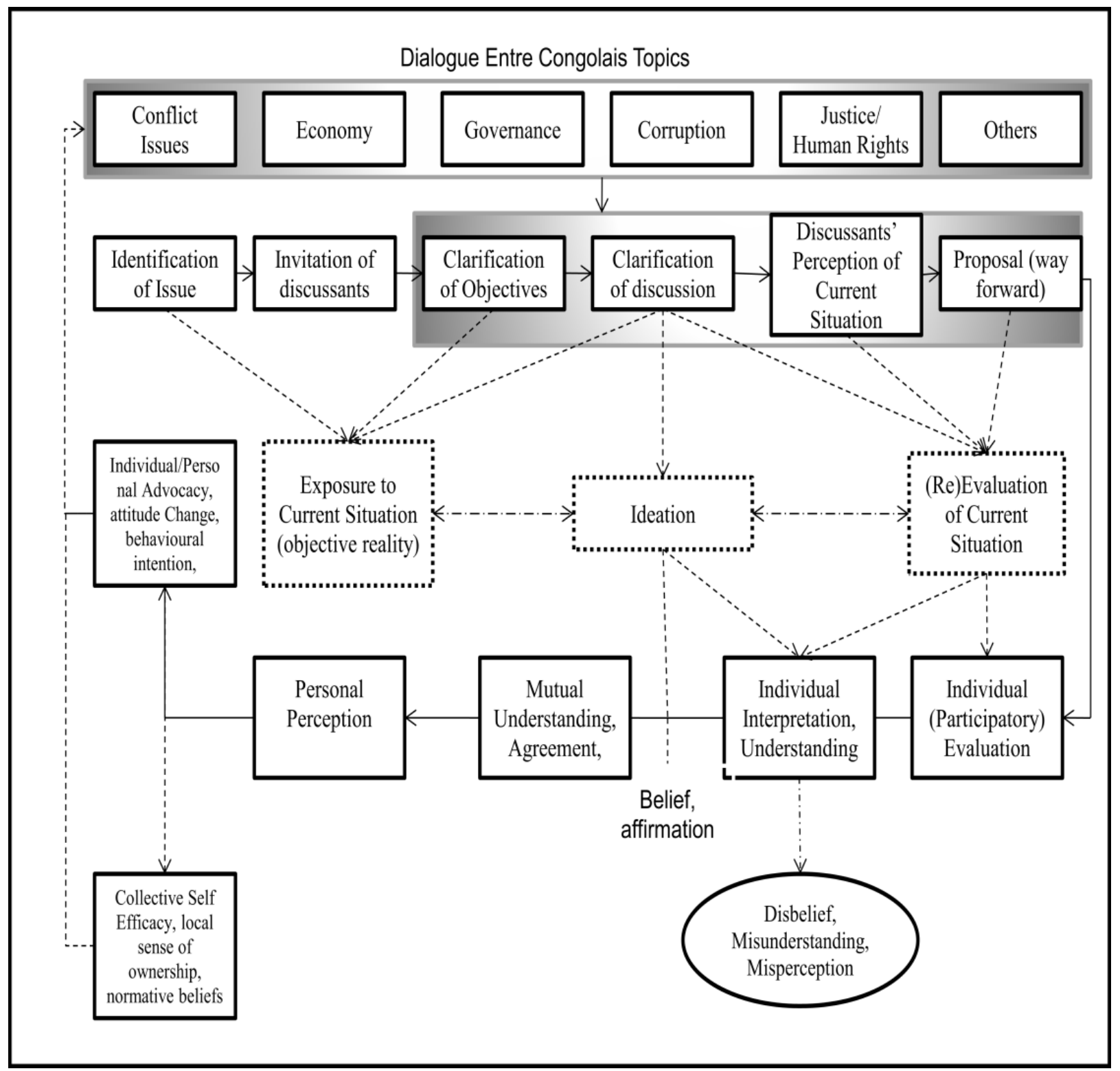

Figure 1. Process of perception change in Dialogue groups.

\subsubsection{Re-Evaluation of Current Situation}

Three salient elements in Dialogue defined participants' constantly evolving evaluation of realities: clarifications of topics (in Dialogue, discussion issues are first explained and the background information provided); Dialogue discussants' expressions of their discursive perceptions of the issues clarified based on their own world view; and proposal for a way forward on the issues-usually summed up by the moderator. Throughout the process of listening, each participant's impressions of the issues and related phenomena were constantly redefined along with their understanding and interpretation of the issues. Understanding and personal interpretation of the issues were influenced by each participant's re-evaluation of the issues after exposure and greater knowledge. Comments at focus groups reflected not only a greater depth of knowledge on issues but also a larger breadth of analyses by individual participants on the issues.

\subsubsection{Personal Perception}

Personal Perception of the issues relating to conflict transformation processes, intervention mechanisms and the impediments thereof reflected, not necessarily the views purveyed by discussants on Dialogue, but a new stream of perception borne out of personal interpretation, mutual agreement and understanding. Conflict transforms perceptions of self, the Other and the issues in contention (Lederach, 1995, 1997). Lederach's works have shown that a salient impact of conflict on the communication patterns of conflict groups is a decreased ability to articulate one's intentions in a manner that is credible and devoid of propaganda and rhetoric. When compared with the control group, Dia- 
logue-treated participants shared meaning in a more robust and reflective manner. Moreover individual participants re-engaged with the ethnic Other, based not on the negative descriptive languages found in the control groups' expressions, but on an objective and logical evaluation of the self, the Other and the contending issues such as citizenship and barriers to peace. At personal levels, personal advocacy was noticed in participants' comments about various community engagement activities they had become involved in since their participation in the research. At group levels, although there were lesser agreements on topics discussed, there was a greater level of collective self-efficacy, and collective sense of ownership of transformation processes.

In summary, Dialogue discussions were horizontal and transactional. They enabled individual and group level evaluation and re-evaluation of the different positions purveyed by discussants. New levels of perception that emerged from understanding and belief promoted individual advocacy, perception and attitudinal change. In situations where the new thinking is transmitted through social or informal means within the community, social impact can be achieved through collective self-efficacy which in turn can have actual effects on the events discussed on Dialogue.

\subsection{Ethnic Awareness and Perceptions of Victimhood in Gutahuka Groups}

Congolese autochthons exposed to Gutahuka expressed more awareness of the ethnic and political divisions that can deter future social and political relationships. Across contexts, except in Fizi with its peculiar socio-cultural blend of Hutus and autochthons, Gutahuka-exposed autochthons were pessimistic about possibilities of a unified Congolese army involving all the ethnic groups including settled Hutus. This contrasts with opinions of Dialogue listeners who recommended that questions of citizenship be resolved once and for all to enable communities to integrate peacefully. Generally, Dialogue participants believed there were opportunities for integration and a mutually rewarding relationship across ethnic groups if issues of identity and citizenship were resolved. A salient pattern of difference in beliefs between the listening groups is that Dialogue listeners showed more empathy towards Hutus than listeners of Gutahuka. In discussing their perceptions of Victimhood, Autochthon listeners of Gutahuka did not see Hutus as victims of the conflict whereas autochthon Dialogue listeners across all contexts believed Hutus were among the main victims of the conflict, implying as it were, a greater sense of empathy towards the Hutus. In one of the Gutahuka groups (Mwenga), Hutus were even identified as the Villains. Dialogue listeners' perception of Villainity centred on corrupt politicians.
It had been envisaged at the beginning of the study that exposure to the Other's programme would deepen an understanding and empathy with the Other's issues, but the reverse has been the case in autochthon listeners of Gutahuka. They perceived Hutus as the problem and expressed the normative appeal in Gutahuka that peace in the DRC is linked to FDLR militants (embedded in Hutu communities) repatriating to Rwanda. Interestingly, Hutu Dialogue listeners had mixed perceptions of Victimhood and Villainity that did not show any particular pattern. Again, this reflects the discursive and analytical nature of the programme Dialogue.

Beliefs expressed by autochthon listeners of Gutahuka have far-reaching implications on contentious debates on the impacts of exposure to contents meant for the Other in deeply divided societies and the overarching debates on the role of the media in reinforcing dominant power relations in the society. There has been a retinue of interesting scholarly works that support the position that the media convey mainstream outlooks and normative beliefs about behaviour (Barak, 1994; Gerbner, Signorielli, \& Morgan, 1982; Signorielli \& Morgan, 1989; among others). Indeed, Barak (1994) has observed how media contents identify heroes, villains, and neutral characters and associate them with specific traits, beliefs or forms of behaviour and in other cases label and stigmatise certain activities and individuals or groups as antisocial, deviant or undesirable. He posits that such associations have relative implications on social control. Also, Mutz (1998) has written brilliantly on the "impersonal" nature of influence by media portrayals of attitudes, beliefs or experiences of collectives outside an individual's personal life space. She has argued for "impersonal influence" to be taken more seriously because of its potential to expand contemporary understanding of social influence processes from media portrayals of indirect associations. This research provides important evidence within the spheres of Barak's (1994) "symbolic deviance" and Mutz' (1998) "impersonal influence". By constantly calling on FDLR militants to repatriate, Gutahuka labels or stigmatizes Hutus in general as deviant and undesirable. This is because there is a social reality that associates the FDLR with Hutus and vice versa, which in turn creates unspoken assumptions and cognitive framing of the Hutu Other as "foreign", "unwelcome", "deviant" and "undesirable" among autochthon listeners of the programme. Although autochthons are not the target audience for the programme, they are as exposed if not more exposed to it as the targets themselvesmore exposed because FDLR militants in the forests are prevented by their commanders from listening to the programme for fear they would be convinced to surrender. Obviously Radio is not selective in its reach; hence audiences who are not targets of a particular intervention programme but are exposed to it do end up consuming the programme. In the case of Gutahuka, 
although MONUC presents the programme in Kinyarwanda-the language spoken among Hutus in Rwanda, most Congolese in the Kivus understand and speak Kinyarwanda fairly fluently having lived side by side with Rwandans for several years. For non-targets, Gutahuka's messages construct "symbolic deviance"involving unspoken assumptions, associations and framing of the FDLR combatant as an "unwelcome" or undesirable Hutu. This in turn impugns on non-Targets' perception of the Hutu Other. The "Otherization" of Hutus is further deepened by media reports of joint military activities against the FDLR. An autochthon Gutahuka group member in Mwenga said of Hutus: "there must be a problem with you when everybody is pursuing you". The result is what Barak (1994) terms "symbolic punishment" through stigmatisation or labelling of the Hutu Other as antisocial, deviant or undesirable. Such negativity may not be expressed explicitly in Gutahuka but dynamic interactions of Gutahuka's messages and implicit normative appeals with unspoken assumptions rooted in an epistemic association of the FDLR with Hutus and vice versa lead to the construction of symbolic deviance not intended by the programme creators.

Although Gutahuka's messages and normative appeals (see Figure 2) are intended to restore peace in South Kivu by achieving voluntary repatriation of FDLR elements and Hutu civilians, they do have negative implications on social relations between autochthons and the Hutu Other when considered against the backdrop of a social reality or discursive formation that associates the FDLR with Hutus and vice versa-an association taken for granted or unaccounted for in the programme. By problematising the FDLR-Hutu, Gutahuka created or deepened animosity towards Hutus among autochthon listeners in three of the four contexts researched. In the fourth context, Fizi, there is a historical reality that supports a mutual alliance and cordial relations between the autochthons and Hutus. This in turn is supported by local influentials that purvey localised subjective realities or norms. Fizi Participants' engagements with objective realities or ongoing events and with the mediated reality of Gutahuka were thus conditioned by stronger historical and subjective realities which make up the discursive formation of their society.

In the other contexts however, Gutahuka further reinforces the dominant power relations by depicting the FDLR as the problem and not the breakdown in social relations and other structural causes of the conflict. The result has been a "we-they" cognitioning and expression of relations between the autochthon "self" and the Hutu Other. This is evident in a comment by an autochthon Gutahuka listener in Walungu: "They (Hutus) have raped thousands of our women, killed thousands of our young men, stolen everything they can steal, they are the ones that have kept us where we are today".

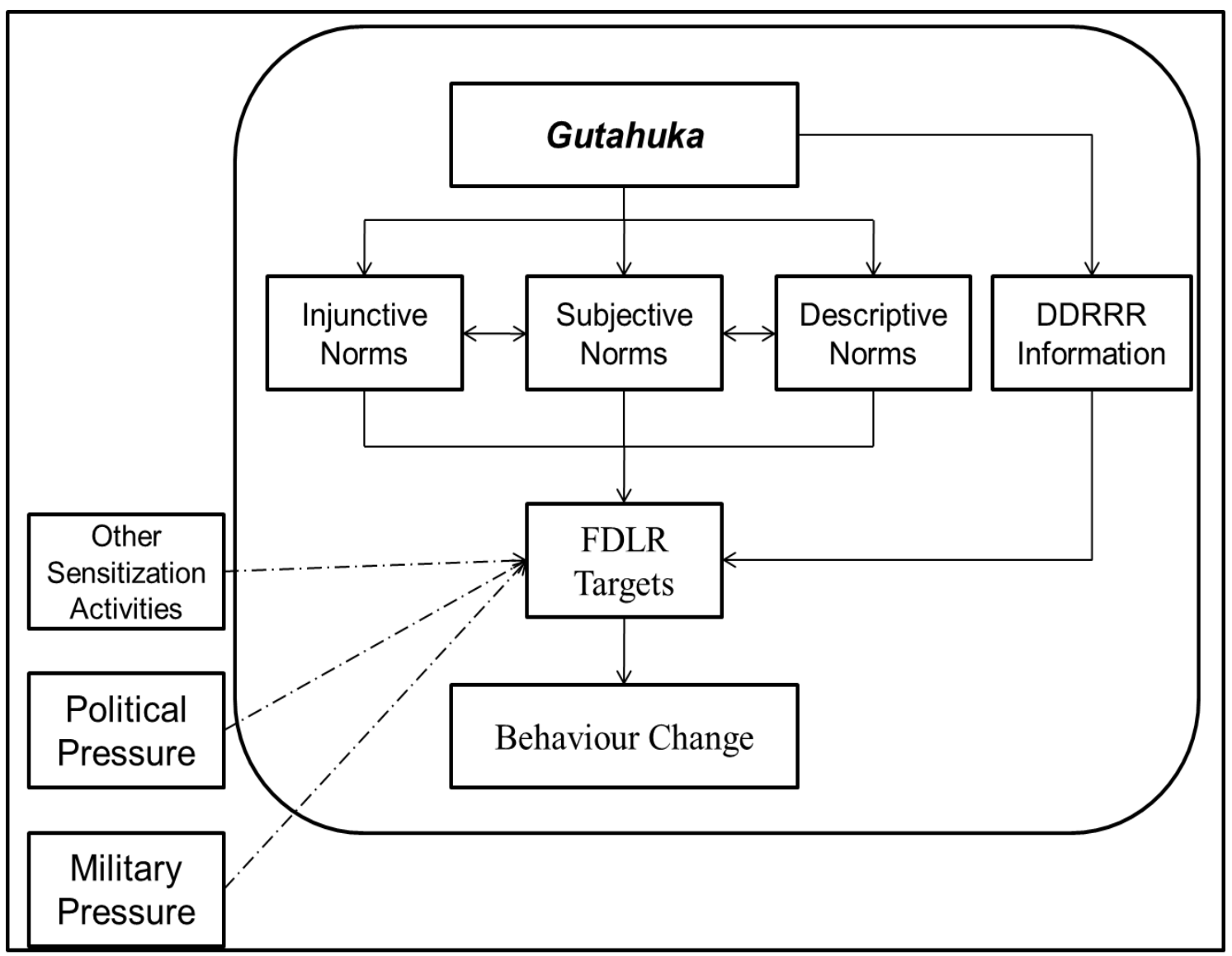

Figure 2. Appeal to norms: The Gutahuka communication strategy. 
The calibration of the Hutu as a normative Other is only evident among autochthon Gutahuka listening groups. Although living within the same contexts with Hutus, and having regular interpersonal interactions with them, perception of Hutus in three of the contexts seem to be influenced more deeply from Gutahuka representations of the FDLR/Hutus than from their day-to-day interactions with them. This corroborates Mutz" position that people respond "to a mediaconstructed pseudoenvironment-rather than their immediate personal experiences or those of friends and acquaintances" $(1998$, p. 6).

At a broader level, media (re)constructed reality is not necessarily about the direct persuasive or influence potentials of media messages that set out to change behaviour or a viewpoint. Mediated reality is the media superstructure's refinement of the subjective reality (or opinions or experience of influential collectives) purveyed by elites or political/military actors to influence citizens (as in the case of purveyors of subjective norms in Gutahuka). Because of the media's expertise in matters that are beyond the realm of citizens' personal experiences, they are perceived as more reliable sources of information. Mutz (1998) has argued that media content is particularly well suited and used as a credible channel of information about such collective subjective realities. Essentially, in the context of a violently divided society where, as Lederach (1997) has written, perceptions of self, the Other and the issues in contention are constantly altered resulting in a "contaminated" interpretation and understanding of the Other's intentions, media intervention contents have strong potential impacts even on non-Target listeners. As findings have shown, non-Target listeners exposed to contents aimed at changing the behaviour of the ethnic Other resulted in more negative perceptions of the Other compared with participants that listened to a political debate programme-Dialogue. In the communities researched, participants were exposed to a communicative sphere that drew on four contending realities with varying degrees of potential impacts on interpretation and engagement with mediated contents: Historical Reality, Objective Reality, Subjective Reality and Mediated Reality.

\subsection{Contending Realities in Narrative Frameworks of Dialogue and Gutahuka}

Participants' comments during focus groups show that communication patterns of groups researched were overwhelmingly rooted in their memory or knowledge of previous conflicts, events or interrelationships. Historical realities define the epistemes within which metaphors, memories, discursive practices and communication patterns of each network are negotiated. Hugh Miall (2004) has argued that collective memories are a salient element that should be of interest to conflict transformers because memories of past conflicts determine groups' expectations in future relationships and significantly determine their behaviour toward the Other and how meaning is shared. In this study, key influentials or purveyors of subjective realities were themselves influenced by historical realities which in turn infected their communication patterns. Participants in the focus groups were at the intersection of a triad of realities that in addition to other factors defined their perceptions. Those exposed to a mediated reality that did not provide a platform for objectively engaging and debating with the historical and subjective realities in the triad were subjected to the normative influences of those realities in their engagement with media contents. Exposure to the Others' media contents within a communicative sphere or intersection that is hostile to the Other created a stronger negative opinion of the ethnic Other. The tendency to blame the Hutu-Other for the misfortune of the autochthon-self was intensified with exposure to the $\mathrm{Hu}$ tu-Other's behaviour change messages. In each context studied, historical realities defined how participants expressed their views, how programme messages were interpreted and the various ways they sought alternative mediated or socially transmitted information that met their peculiar needs (please see Figure 3). Exceptions were found however among participants exposed to a media platform where the contending realities were confronted and debated.

\section{Conclusion}

Radio is a ubiquitous mass medium-generally received by all within the reach of the transmitting station. Hence there are possibilities that non-Targets may be exposed to behaviour-change contents not meant for them. This study engaged with the question of how disparate networks operating within homogenous contexts engage with information products meant for the Other. There is evidence in this research that exposure of non-targets to behaviour change contents meant for the Other can create hostility against the targets. Congolese autochthons exposed to Gutahuka during the period did not develop a sense of affinity with the Hutus as envisaged, but hostility. Across contexts, they expressed the belief that if Hutus and all Rwandans left the DRC there would be peace, reflective of the normative appeals in Gutahuka that portray the armed group, the FDLR as barriers to peace. Epistemic associations between the FDLR and the Hutu impelled autochthon participants to express sentiments of undesirability regarding not only the FDLR but also the Otherised Hutu. Here was arguably one of the sharpest contrasts between perceptions of Autochthon listeners of Dialogue and their Gutahuka listening counterparts. Autochthon Dialogue listeners were more empathetic with what they saw as plight of the Hutus. 


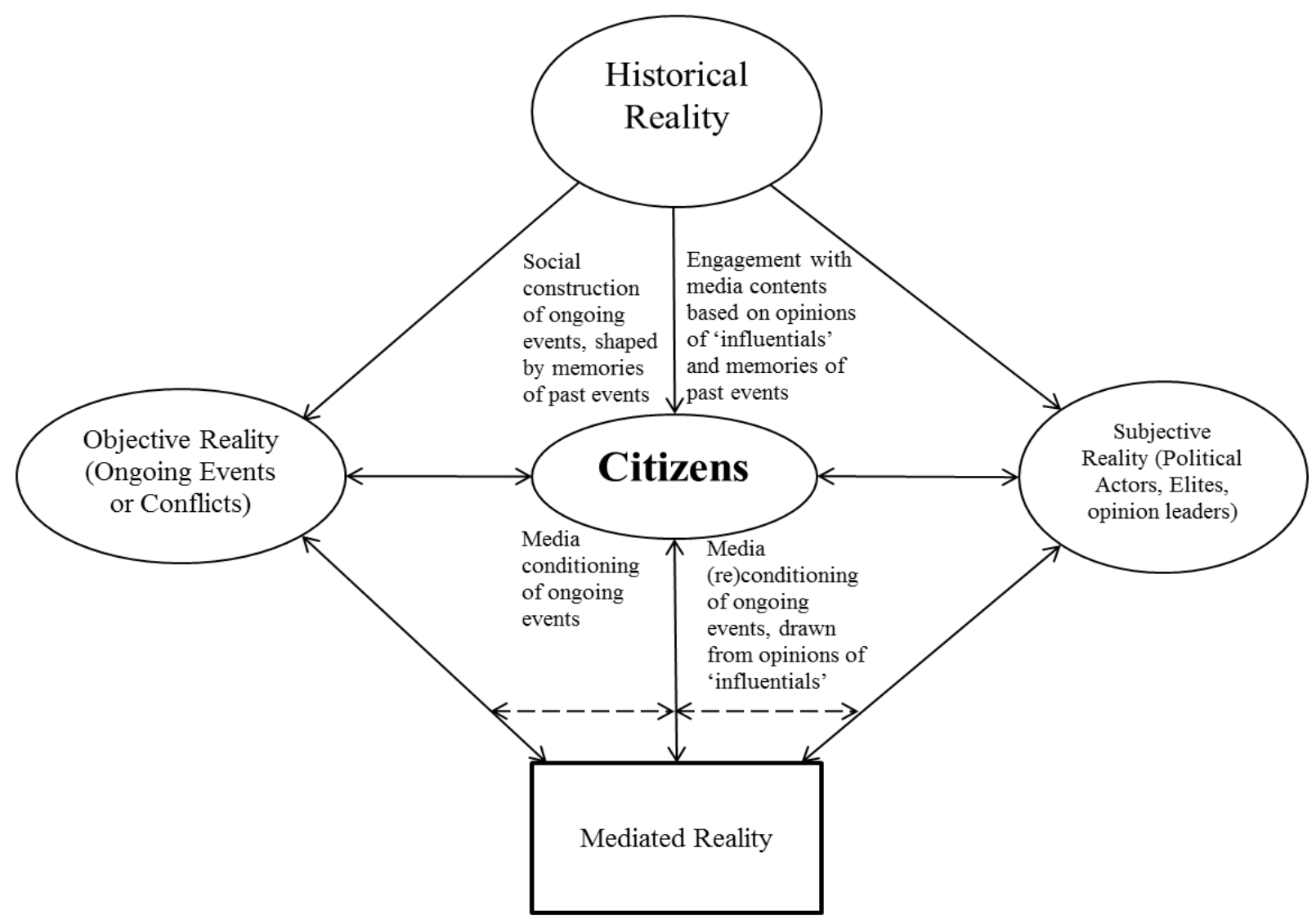

Figure 3. Contending realities in conflict settings.

Across all contexts of the study, they identified Hutus as one of the main victims of the war and expressed emotions of empathy to their plight. Among the Gutahuka listeners, there was no mention of Hutus at all (even passively) as victims of the conflict. The emerging implication is that Dialogue listeners were more analytical of the conflict situation and the dynamics thereof including issues of causality, casualty, victimhood and villainity, and the various military operations targeted at the FDLR (but inevitably also fatally affecting Hutu civilians and refugees) as a basis for their perception of Hutus as victims. Gutahuka listeners on the other hand perceived the various military operations against the FDLR as evidence of the undesirability of not just the FDLR fighter but also his (the fighter's) family. Simply put, the same objective reality of military operations against the FDLR elicited two fundamentally different perceptions from listeners within the same network and contexts based on the nature of intervention programmes each was exposed to.

Two critical implications emerge. First, hate contents are not only the ones that are overtly hateful. Messages targeted at specific groups for the purpose of achieving behavioural change can lead to alienation and hostility toward the Target group by the Other (non-target) groups exposed to the messages. The implication is that media intervention contents that purvey a narrative without first understanding how it interacts with other epistemic narratives, metaphors and historical realities on ground run the risk of deepening rifts between groups and escalating the conflict. Another implication is that contextually associated individuals or social groups do not always have homogenous interpretation, perception and/or decoding of media messages. At the core of these discursive perceptions is the ideological orientation of messages audiences are exposed to and how they interact with historical and subjective realities on ground. Whereas Gutahuka called on FDLR militants to disarm and return, Dialogue encouraged objective and pluralistic analyses of the conflict including the crises situation and the underlying issues within a narrative framework that demands of listeners a level of iterative evaluation, understanding and interpretation to achieve individual and collective belief or disbelief. This can explain why Dialogue listeners across contexts and networks perceived failed interventions of the DRC government as one of the main barriers to peace. This shows that Dialogue listeners' construction of conflict transformation processes and conflict multipliers rest on the activities or inactivities of the democratically elected government in the DRC and not the presence of Hutu "foreigners". Though dissatisfied with the intervention activities of the government, Dialogue listeners' responses showed they perceived the government as endowed with the legitimacy and political license needed to tackle the problems. 
An essential ingredient in the democratic process of the DRC - a country that has experienced over 40 years of brutal military rule out of about 55 years of self-rule, is recognition of the legitimacy of the democratically elected government and the new institutions set up to support democracy and good governance. Importantly, Dialogue participants' discussions of prescriptions for conflict transformation centred on specific actions the government and its institutions could take to achieve peace. Interestingly, autochthon Dialogue listeners did not see any ethnic group as a barrier to peace, and neither indeed did Hutu Dialogue listeners. Whereas Hutu Gutahuka listeners saw the "Tutsi government" of Rwanda as the greatest barrier to peace, Hutu Dialogue listeners saw the inactions of the Congolese Government as barriers to peace-corroborating the perception of autochthon Dialogue listeners of the Go-DRC's legitimacy and capability to live up to its mandate if supported and if issues of corruption are solved.

Through the programme Dialogue, Radio Okapi performs more than mere cognitive functions of providing objective information. The programme also undertakes interpretative functions including analyses, evaluation, assessments and comments. Discussants in some cases are not only the authors of the cognitive and interpretative elements of Dialogue but also the authors of the very issues they seek to interpret. Through the programme, they are able to present their arguments within their own narrative frameworks. Their narrative frameworks are different from the narrative frameworks in Radio Okapi's news discourses with its inherent gate-keeping appendages. Arguably, this represents the liberal democratic role of Radio Okapi in the DRC. By mediating objective realities of ongoing events and subjective realities purveyed by political elites, Dialogue provides elites a raw forum to criticise policy decisions and to comment on other issues of popular concern while also affording citizens an opportunity to participate in the questioning, evaluation and interpretation processes.

Despite its good work however, Radio Okapi has had an immensely difficult time in the DRC, with two of its journalists killed ${ }^{3}$ and several others intimidated by armed gangs ${ }^{4}$. In the eastern region of the country, Radio Okapi has faced the ever-present allochthony/autochthony (foreigner/local) crises in terms of questions of foreign content and ownership in a region

\footnotetext{
${ }^{3}$ Radio Okapi Journalist Didace Namujimbo was shot dead in Bukavu in November 2008 by unknown gunmen, 17 months after another Radio Okapi Journalist Serge Maheshe was also killed in Bukavu.

${ }^{4}$ The most recent being the brutal beating on August 72009 of Paulin Munanga, Radio Okapi's Provincial correspondent in Lubumbashi by security agents of Agence Nationale des Renseignements, (ANR) while covering a demonstration by human rights activists in Katanga.
}

where citizenship and nationality are contested issues. Though the station has an array of programmes aimed at various networks and actors in the DRC conflict, there is the potential risk of a crisis of message-what message for whom and with what effects on other groups? Besides, although, Radio Okapi is directly run by Swiss based Hirondelle Foundation, it is joined at the hip with the UN and is subject to reservations local folks have about UN peacekeepers. In its over 10 years in the DRC, the UN has had to deal with various controversies regarding its Peacekeepers-ranging from accusations of rape, arms dealing, trade in conflict diamonds and coltan, to negation of their responsibility to protect civilians under threat of violence.

Contemporary works on Information Intervention have tended to concentrate on rationalising intervention. There have been far lesser studies on the nature of intervention, the framework for intervention and the composition of interveners. Krug and Price (2002) have made a compelling case for and proposed a module that can be generically applied in post-conflict settings. But their module is focused primarily on regulatory frameworks and issues of governmentality, media reform and governance.

This work extends the frontiers of the discussion by exploring, not only the actual contents of intervention media but also the impacts of specific contents on groups in societies violently divided along ethnic cleavages. Today, Information Intervention and Public Diplomacy activities by foreign states, NGOs and IGOs as a tool for Peacebuilding or preventing genocide have become normatively acceptable in the international community. For example, in 2009 the UN Support Office for AMISOM (UNSOA) in Somalia outsourced a major PIO component to a communication consulting consortium after an openly advertised bidding process which drew tenders from NGOs including Hirondelle Foundation. While various factors determine the outcome of UN procurement processes, the UN's decision to award the contract to a private consulting consortium is instructive. If anything, it suggests that the UN is becoming more confident with its new outsourcing of public information components. Part of the UNSOA outsourcing deal, is a Radio component-Radio Bar-Kulan which is run by Okapi Consulting-a member of the consortium ${ }^{5}$. Along this trajectory, this study moves the debates from questions of legitimacy of media intervention to questions of who should intervene as well as the nature and effectiveness of specific media intervention contents and their impacts in real world settings.

Furthermore, the methodological approach used in the study moves the debates beyond prediction models and/or retrospective rationalisations frequently

\footnotetext{
${ }^{5}$ Okapi Consulting has nothing to do with Radio Okapi. It is a South African-based private consulting company headed by David Smith, former MONUC's Chief of Public Information.
} 
used in media impact evaluation processes of this nature. The research was designed bearing in mind the affinity for narratives and story-telling of the communities researched. It was built on real time, real world subjects and contexts involving working with real people within real contexts of an ongoing conflict setting-intact with emotions of fear, anger and guilt as well as rumours and other socially transmitted information which have potentials of affecting audience engagements.

Findings provide instruments with which operational researchers or media intervention practitioners can compare predictions and rationalise impacts as they happen, in future conflicts. Furthermore findings have implications on contemporary understanding of the relative importance of communication models and their interactions within conflict settings where the media is used as a tool for violence or for transformation and Peacebuilding.

The implication of findings in this study is that contents for African audiences need to draw and build on the rich oral traditions and traditionally transactional processes of information and meaning sharing. Such contents should first map existing narratives to identify conflicting messages. Secondly, explore using participatory processes, new narratives that transcend historical realities within which conflict parties weave their narratives. Thirdly, design the new narratives within an interactive framework that engages with and challenges conflicting ones.

Information intervention is a concept worthy of continued debates. Within the realm of Public Diplomacy, information intervention figures prominently, not as an appendage for explaining mandates or rationalising an intervention, but as a virile tool for stimulating public debates on the common good. And within military spheres of psyops, information intervention figures, not only as a force multiplier but as a key component of strategy. This study emphasises the need to keep the approaches that underlie both doctrines far apart particularly during the post-conflict reconstruction phase.

In summary, findings of this study show that in violently divided societies, Information Intervention approaches aimed at achieving attitudinal and/or behavioural change by appealing to social norms can be ineffective if not counter-productive. But an informative approach involving the use of narratives that stimulate discursive discussions on the common good, a collectively imagined future and issues of good governance can open up a sphere for participation, social interaction and civic engagement.

\section{Acknowledgments}

The author acknowledges the generous financial support of the British Institute in Eastern Africa (BIEA) for the field elements of this research.

\section{Conflict of Interests}

The author declares no conflict of interests.

\section{References}

Afoaku, O.G. (2002). Congo rebels: Their motivations and strategies. In J. F. Clark (Ed.), The African stakes in the Congo War (pp. 109-128). New York, NY: Palgrave Macmillan.

Autesserre, S. (2006). Local violence, national peace? Post-war "settlement" in the Eastern D. R. Congo. African Studies Review, 49(3), 1-29.

Barak, G. (1994). Media, society and criminology. In G. Barak (Ed.), Media, process, and the social construction of crime: Studies in newsmaking criminology (pp. 3-45). New York \& London: Garland Publishing Inc.

Crisis Group. (2009). Congo: A comprehensive strategy to disarm the FDLR (Africa Report No. 151). Brussels: Crisis Group.

Domeniconi, M. (2004). How a radio station keeps population informed: Complex return to normality in D. R. Congo. In B. James (Ed.), Media: Conflict prevention and reconstruction (pp. 43-45). Paris, France: UNESCO.

Feeley R., \& Thomas-Jensen, C. (2008). Past due: Remove the FDLR from Eastern Congo. (Enough Strategy $\mathrm{Pa}$ per, No. 22).

Gerbner, G., Signorielli, N., \& Morgan, M., (1982). Charting the mainstream: Television's contributions to political orientation. Journal of Communication, 32(2), 100-127.

Hilmes, M. (2002). Rethinking radio. In M. Hilmes \& J. Loviglio (Eds.), Radio reader: Essays in the cultural history of radio (pp. 1-20). London: Routledge.

IRC. (2008). Mortality in the Democratic Republic of Congo: An ongoing crisis. New York, NY: International Rescue Committee.

Jacob, J. U. (2010). Rethinking information intervention in violently divided societies: MONUC's public information operations and conflict transformation in the Democratic Republic of Congo (Unpublished doctoral dissertation). University of Leeds, UK.

Jacob, J. U. (2015). Influencing the information domain: The UN's information intervention in the Democratic Republic of Congo. In W. Mano (Ed.), Racism, ethnicity and the media in Africa (pp. 178-198). London: I. B. Tauris.

Kincaid, D. L. (1993). Communication network dynamics, cohesion, centrality and cultural evolution. In G. A. Barnett \& W. Richards (Eds.), Progress in communication science series (Vol. XII) (pp. 111-132). New York, NY: Ablex.

Krug, P., \& Price, M. (2002). A module for media intervention: Content regulation in post-conflict zones. In M. Price, \& M. Thompson (Eds.), Forging peace: Intervention, human rights and the management of 
media space (pp. 148-174). Edinburgh: Edinburgh University Press.

Lederach J. P. (1995). Preparing for peace. New York, NY: Syracuse University Press.

Lederach, J. P. (1997). Building peace: Sustainable reconciliation in divided societies. Washington DC: United States Institute of Peace.

Lusaka Ceasefire Agreement. (1999). Democratic Republic of Congo: Lusaka ceasefire agreement. Retrieved from http://peacemaker.un.org/sites/peacemaker. un.org/files/CD_990710_LusakaAgreement.pdf

McGuire, W. G. (1986). The myth of massive media impact: Savagings and salvagings. In G. Comstock (Ed.), Public communication and behavior (Vol. 1) (pp. 175259). Orlando, FL: Academic Press.

Miall, H., (2004). Conflict transformation: A multidimensional task. In A. Austin, M. Fischer, \& N. Ropers (Eds.), Transforming ethnopolitical conflict: The Berghof handbook (pp. 67-90). Berlin: VS Verlag für Sozialwissenschaften.

Mounoubai, M (2010, March 9). Personal interview.

Mutz, D. C. (1998). Impersonal influence: How perceptions of mass collectives affect political attitudes. Cambridge: Cambridge University Press.

Nest, G., Francois, G., \& Kisangani, E. (2006). The Democratic Republic of Congo: Economic dimensions of war and peace. Colorado: Lynne Rienner Publishers.

Nisbet, E. (2006). The engagement model of opinion leadership: Testing validity within a European context. International Journal of Public Opinion Research, 18(1), 3-30.

Paluck, E. L. (2007). Reducing intergroup prejudice and conflict with the mass media: A field experiment in Rwanda (Unpublished Doctoral dissertation). Yale University, US.

Paluck, E. L. (2009). Reducing intergroup prejudice and conflict using the media: A field experiment in Rwanda. Journal of Personality and Social Psychology, 96(3), 574-587.

Prunier, G. (2009). From genocide to continental War: The 'Congolese' conflict and the crises of contemporary Africa. London: HURST Publishers Ltd.

Radio Okapi. (2006). Values of Fondation Hirondelle and Radio Okapi. Lausanne: Foundation Hirondelle.

Rawnsley, G. (1999). Cold War propaganda in the 1950s. Basingstoke: Macmillan.

Rawnsley, G. (1996). Radio diplomacy and propaganda:
The $B B C$ and VoA in international politics, 1956 1964. Basingstoke: Macmillan.

Rimal, R. N., \& Real, K. (2003). Perceived risk and efficacy beliefs as motivators of change: Use of the risk perception attitude (RPA) framework to understand health behaviors. Human Communication Research, 29(3), 370-399.

Rogers, E. M. (1995). Diffusion of innovations (4th ed.). New York, NY: Free Press.

Rogers, E. M., \& Kincaid, D. L. (1981). Communication networks: Toward a new paradigm for research. New York, NY: Free Press.

Signorielli, N., \& Morgan, M. (1989). Cultivation analysis. Newbury Park, CA: Sage Publications.

Squier, S. M, (2003). Communities of the air: Introducing the Radio world. In S. M. Squier (Ed.), Communities of the air: Radio century, radio culture (pp. 1-38). Durham, NC: Duke University Press.

Swarbrick, P. (2004). DDRRR: Political dynamics and linkages. In M. Malan \& J. G. Porto (Eds.), Challenges of peace implementation: The UN mission in the Democratic Republic of the Congo (pp. 166-167). Pretória: Institute for Security Studies.

Thakur, M. (2007). Demilitarising militias in the Kivus (Eastern Democratic Republic of Congo). African Security Review, 17(1), 52-67.

Turner, T. (2007). The Congo wars: Conflict, myth and reality. London: Zed Books Ltd.

UNHCR. (2009). Global report: Democratic Republic of Congo. UNHCR. Retrieved from http://www.unhcr. org/gr09/index.html

United Nations Office for the Coordination of Humanitarian Affairs. (2009). DRC: Humanitarian situation in South Kivu (Situation Report No. 2). New York: OCHA.

United Nations Security Council. (1999). Report of the Secretary-General on the situation in the Democratic Republic of the Congo (S/1999/790). Retrieved from http://www.un.org/en/ga/search/view_doc.asp?sym bol=S/1999/790

United Nations Security Council. (2010). Security Council resolution 1925 (S/RES/1925). Retrieved from http:// www.securitycouncilreport.org/atf/cf/\%7B65BFCF9B -6D27-4E9C-8CD3-CF6E4FF96FF9\%7D/DRC\%20S\%20 RES\%201925.pdf

United States Office of the Chairman of the Joint Chiefs of Staff. (2010). Psychological operations (Joint Publications 3-13.2). Washington, DC: CJCS.

\section{About the Author}

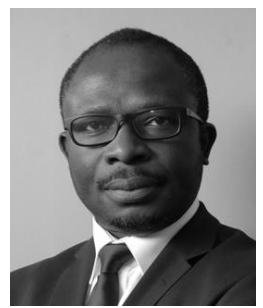

\section{Dr. Jacob Udo-Udo Jacob}

Jacob Udo-Udo Jacob is Associate Dean of the School of Arts and Science and Chair of the Communications and Multimedia Design program at the American University of Nigeria, Yola. Jacob's research interest is located at the intersections between communications and politico-cultural change in contemporary society. He earned his PhD in Communications Studies from the University of Leeds, United Kingdom. In addition to researching the UN's Public Information Operations in the DRC, Jacob has worked on countering violent extremism projects and communication campaigns in North-East Nigeria. 